Goldschmidt 2021 Abstract

https://doi.org/10.7185/gold2021.5835

\section{Study of the influence of extraterrestrial matter on microorganisms}

\author{
ANDREY IVANOV ${ }^{1}$, VYACHESLAV SEVASTYANOV ${ }^{1}$, \\ ALEXEY DOLGONOSOV ${ }^{1}$, BORIS SHNYKIN ${ }^{1}$, TATYANA \\ IVANOVA $^{2}$ AND ANNA SKRIPNIK ${ }^{1}$
}

${ }^{1}$ Vernadsky Institute of Geochemistry and Analytical Chemistry of Russian Academy of Sciences

${ }^{2}$ Federal Service for Surveillance on Consumer Rights Protection and Human Wellbeing

Presenting Author: aiva1959@mail.ru

It is known that terrestrial microorganisms trapped in space conditions can mutate and become dangerous. Can the extraterrestrial matter of meteorites affect microorganisms? For example, carbonaceous chondrites can contain a wide range of abiogenic organic compounds, and even containing the isotopically heavy form of carbon. In our studies during the cultivation of monoisotopic organisms and the experimental study of ${ }^{13} \mathrm{C}$-SAM during in vitro DNA methylation, an epigenetic effect of isotopicity was found when ${ }^{12} \mathrm{C}$ was replaced by ${ }^{13} \mathrm{C}[1]$. This phenomenon is obviously associated with the conformational effect upon isotope substitution, which can be seen from quantum-chemical calculations when only ${ }^{12} \mathrm{C}$ is replaced by ${ }^{13} \mathrm{C}$ in $\mathrm{SAM}$. It can be seen that the isotopesubstituted SAH formed in the course of the reaction, differing in conformation from the natural one, can lose its affinity for methylase and, as a consequence, its inhibitory effect. This is experimentally confirmed. But can the isotopically heavy abiogenic organic matter of meteorites be epigenetically active for terrestrial microorganisms? To test this idea, three meteorites were selected, differing in isotopic-organic inclusion: Murchison, Efremovka and Chelyabinsk.

The difference in the activity of SAM (S-Adenosyl-Lmethionine) preparations of different isotopes

Fig. 1: Differences in the efficiency of in vitro DNA methylation with the participation of different isotopic forms of SAM:

a - methylation with the participation of ${ }^{13} \mathrm{C}-\mathrm{SAM}$

$\mathrm{b}$ - methylation with the participation of SAM of natural isotopic composition

Fig. 2: Computer simulation using quantum-chemical methods of calculation shows how significantly chemically identical compounds with different isotopic composition can differ in conformation:

a - SAH conformer of natural isotopic composition

b $-{ }^{13} \mathrm{C}-\mathrm{SAH}$ conformer

Preliminary results revealed the presence of bacterial activity on the Chelyabinsk meteorite, and the absence thereof on the Murchison and Efremovka meteorites. More in-depth studies can show whether the reproduction of bacteria was suppressed by the abiogenic organic matter of extraterrestrial matter.

\section{References}

1. Ivanov A.A. and others. The effect of loss of conformational affinity of SAH for methylase upon isotope substitution of carbon ${ }^{12} \mathrm{C}$ by ${ }^{13} \mathrm{C} .22$ A.P. Isotope Geochemistry Symposium Vinogradov. October 29-31, Moscow 2019

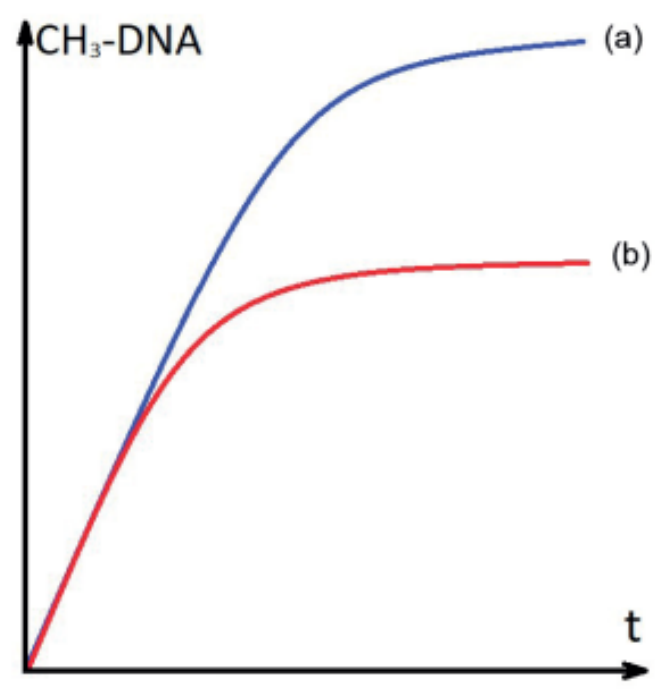

Fig. 1

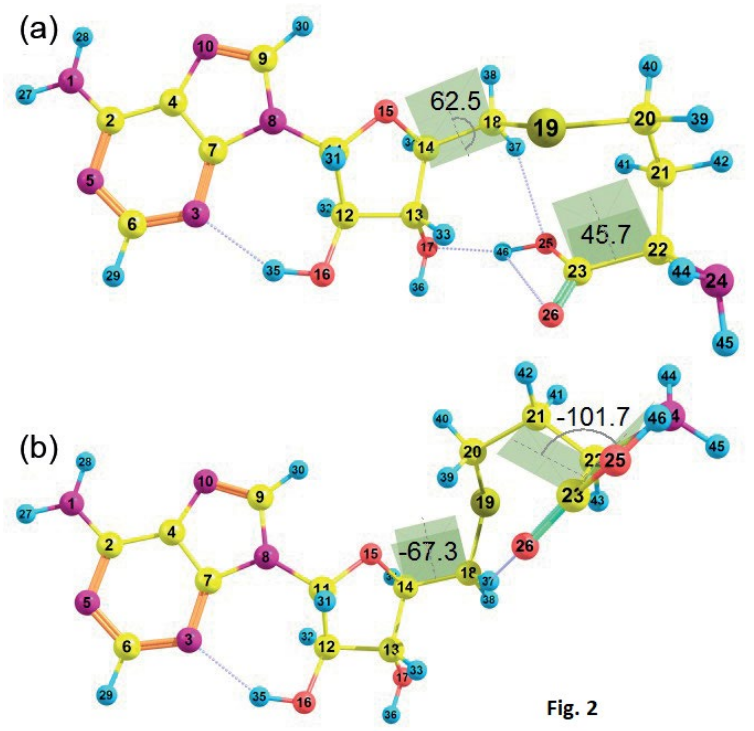

